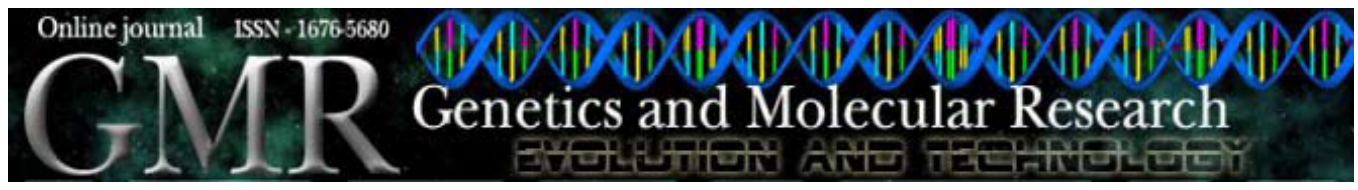

\title{
Amarelinha do Amapá: a carotenoid-rich cassava cultivar
}

\author{
N.M.A. Nassar, P.C. Fernandes, R.D. Melani and O.R. Pires Júnior
}

Universidade de Brasília, Brasília, DF, Brasil

Corresponding author: N.M.A. Nassar

E-mail: nagnassa@rudah.com.br

Genet. Mol. Res. 8 (3): 1051-1055 (2009)

Received April 13, 2009

Accepted June 17, 2009

Published August 25, 2009

\begin{abstract}
Eight cassava (Manihot esculenta Crantz) cultivars, of which four are indigenous to the Amazon region, along with an interspecific hybrid, were assessed for their carotenoid content. They were propagated and are maintained in the living Manihot collection at the University of Brasília. The cultivar "Amarelinha do Amapá", which was collected from the State of Amapá, was found to have a very high content of $\beta$-carotene: $27 \mathrm{mg}$ per $100 \mathrm{~g}$, which is more than 50 -fold higher than in other cassava cultivars. This cultivar, which also has excellent palatability, could be an important source of $\beta$-carotene for cassava breeding.
\end{abstract}

Key words: $\beta$-carotene; Domestication; Genetic diversity; Indigenous cultivars; Palatability; Vitamin A 


\section{INTRODUCTION}

Cassava is one of the most important food staples in several tropical regions, including Northern and Northeast Brazil. The crop may sustain several million people around the tropics (FAO, 2006) where people are highly dependent on cassava for their daily diet. In some tropical locations, vitamin A deficiency in the local diets has been noted. This lack of vitamin A may cause blindness in humans. The consumption of tuberous roots of $\beta$-carotene-rich cultivars may contribute significantly to addressing vitamin A deficiency in such areas. Indigenous clones grown by native people in the Amazon are likely to be sources for $\beta$-carotene-rich cultivars. The domestication of cassava by these native people has led to development of cultivars with high $\beta$-carotene content, because their flesh color plays an important role in the diets and culture of these inhabitants of the Amazon.

The average daily requirement of $\beta$-carotene recommended by the World Health Organization (WHO) is 2.4 to $3.5 \mathrm{mg}$ for adults. Carotenoids are important due to their conversion to vitamin A (e.g., trans- $\beta$-carotene), which acts as antioxidant that helps prevent heart attacks or cancer, lower cataract risks and macular disorders, and enhance the immune system (Krinsky, 1994). The aim of our study was therefore to assess the $\beta$-carotene content of cassava cultivars from Brazil, and to determine the feasibility of selecting $\beta$-carotene-rich clones with excellent palatability.

\section{MATERIAL AND METHODS}

The cassava cultivars Amarelinha-1, Amarelinha do Amapá, ICB diploid, and Amarelinha do Roraima were used in this research. Their roots were washed in running water and peeled, and then immediately processed.

Ten grams of cassava roots was extracted $(5 \mathrm{~mL}$ per gram) with acetone. The plant material was re-extracted twice in order to increase yield. The extract was then filtered and vacuum was used when necessary. The acetone filtrate was mixed with light petroleum and distilled water and then poured into a separation funnel. The aqueous fraction was discarded and the organic fraction was submitted to saponification so that the lipids present in the sample could be separated. The organic fraction was stored overnight in $10 \% \mathrm{KOH}$ solution in methanol $(100 \mathrm{~mL})$ at $12^{\circ} \mathrm{C}$. After saponification, the aqueous fraction was discarded and the organic fraction dried with potassium sulfate. The organic fraction was concentrated on steam at $30^{\circ} \mathrm{C}$, resuspended in $1000 \mu \mathrm{L}$ ethyl acetate and methanol (v/v; 50/50), and separated by high performance liquid chromatography.

Carotene content was determined by high performance liquid chromatography carried out in gradient and isocratic modes, either in normal-mode phase or reverse-phase (Taylor et al., 2006). The analysis of carotenoids was performed using a Shimadzu LC10A chromatograph with an SPD MXA-10 photodiode array detector and a Rheodyne injection valve with $20-\mu \mathrm{L}$ loop. The separation was performed in a Vydac 218TP54 C18 column ( $250 \times 4.6 \mathrm{~mm} \mathrm{ID)}$ with $100 \% \mathrm{MeOH}$ as mobile phase at a flow of $1 \mathrm{~mL} / \mathrm{min}$ at $15^{\circ} \mathrm{C}$, and the effluent was monitored at $450 \mathrm{~nm}$ (Figure 1). Peaks were identified by comparison with the standard compound, with regard to retention time, maximum absorption wavelength $(\lambda \max ; 450 \mathrm{~nm})$, and spectrum profile between 300 and $600 \mathrm{~nm}$, according to Krinsky (1994) and Davies (1976). 

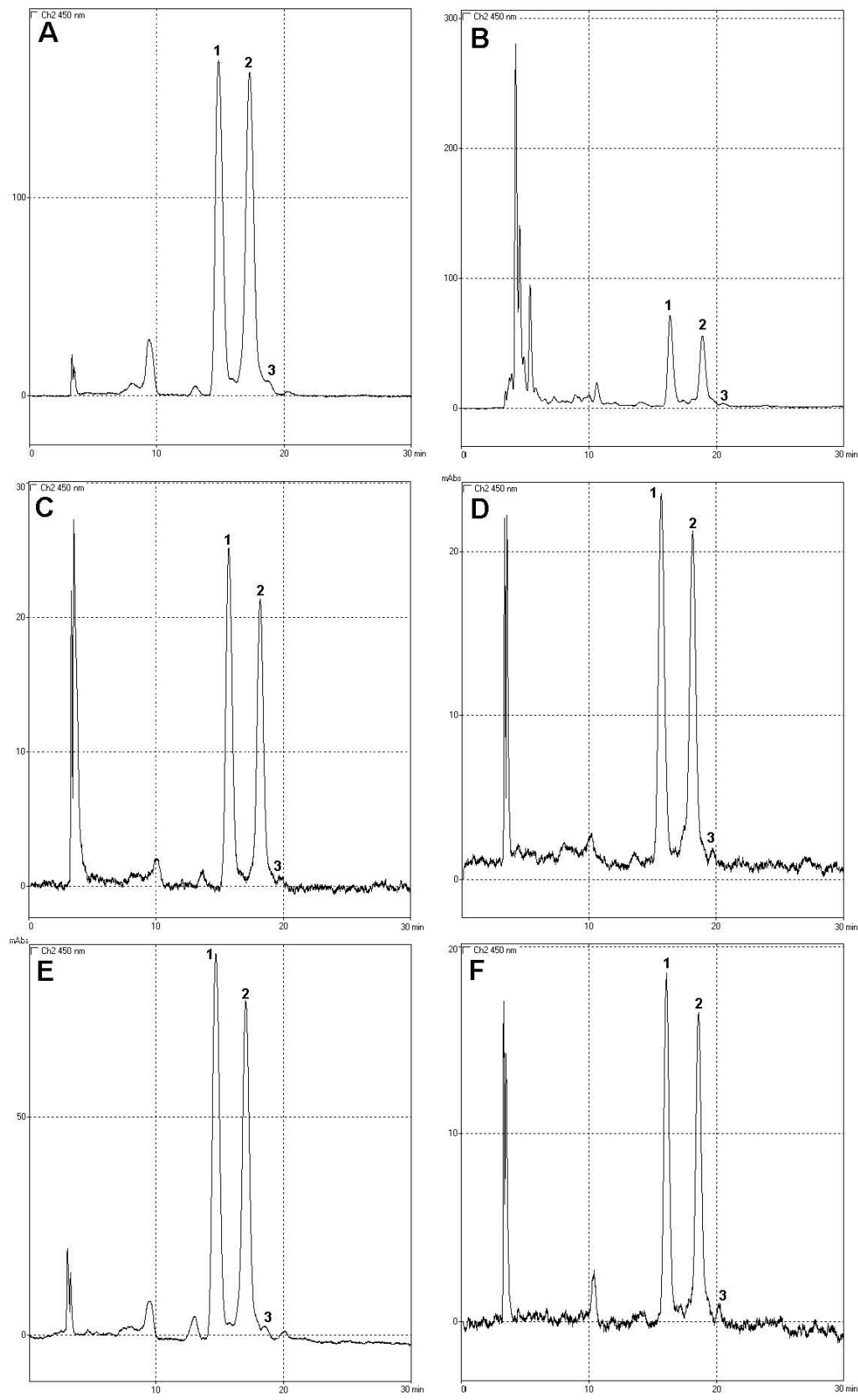

Figure 1. Carotenoid chromatographic profile of cassava cultivars. A. Amarelinha-1. B. Amarelinha do Pará. C. ICB 300 diploid. D. ICB 300 polyploid. E. Diploid 530 F. polyploid 530. High performance liquid chromatography was performed with a Vydac 218TP54 RP C18 column of $250 \times 4.6 \mathrm{~mm} \mathrm{ID,} 100 \% \mathrm{MeOH}$ mobile phase, and flow rate of $1 \mathrm{~mL} / \mathrm{min}$. Numbers 1,2 and 3 in each profile refer to $\alpha$-carotene, cis- $\beta$-carotene and trans- $\beta$-carotene, respectively. 
The calibration curves for $\beta$-carotene and $\alpha$-carotene were built with a minimum tissue concentration from scratch in triplicate. All curves showed a good correlation between peak area and concentration for $\beta$-carotene and $\alpha$-carotene $\left(\mathrm{R}^{2}=1.00\right.$ and 0.98 , respectively). Potential pro-vitamin A was determined by calculating the area under each peak corresponding to the standard curve, expressed in $\mu \mathrm{g} / \mathrm{g}$. The calculation was based on a unit called retinol equivalent (RE), with $1 \mathrm{RE}=6 \mu \mathrm{g}$. The relationship of $1 \mathrm{RE}$ equals $12 \mu \mathrm{g}$ was used as the conversion factor for $\beta$-carotene and $\alpha$-carotene, respectively (Britton, 1995).

\section{RESULTS AND DISCUSSION}

The indigenous cultivar Amarelinha do Amapá showed a very high content of carotenoids, $\alpha$-carotene, $\beta$-carotene, and both cis- and trans- $\beta$-carotene, which is equivalent to $27 \mathrm{mg} / 100 \mathrm{~g}$ (Table 1, Figure 2). This is more than 50-fold higher than the content of other cassava cultivars that we analyzed, namely UnB 101, UnB 102, UnB 103, and UnB 109. This content of $27 \mathrm{mg}$ per $100 \mathrm{~g}$ is 4 -fold greater than that of human daily nutritional needs and surpasses many traditional crop sources of $\beta$-carotene, such as sweet potato. It was not surprising to find such variability and the high carotenoid content in this indigenous cassava. This crop originated in Brazil and it was domesticated about 4000 years ago (Nassar, 1978, 2002, 2003). Early cassava cultivars were the result of mutations, recombination, and human selection by Amazon tribes who sought distinct uses leading to this high variability. They practiced different cultures that favored the yellow color.

\begin{tabular}{|c|c|c|c|c|}
\hline Root & a-carwate & cart-cartesnc & trons-b-cateses & Ratind erpivalent \\
\hline Amardints do Pan & 64.16 & 0.37 & a.t & 5.513 \\
\hline Amardints ds Amaph & 70 & 1.38 & 0.53 & 6.118 \\
\hline LCB 300 dpícid & 57.29 & a.11 & 0.16 & 482 \\
\hline Am ardinta do Dansiana 1 & 69.13 & 0.58 & .65 & 5.97 \\
\hline UnB 164 & & $0.0 \mathrm{t}$ & 0.01 & \\
\hline UnB 162 & & 0.04 & 0.03 & \\
\hline UnB 103 & & 006 & .05 & \\
\hline UnB 160 & & $000 \mathrm{t}$ & 6.02 & \\
\hline UnB 110 & & $0.0 \mathrm{t}$ & 6.01 & \\
\hline
\end{tabular}

Indigenous cassava cultivars are potential sources of high carotenoid content and may play an important role in alleviating hunger among poor people in the tropics. Nassar et al. $(2005,2007)$ reported that some native cassava cultivars from Brazil had high carotenoid content, but that none of them showed a very high level vis-à-vis Amarelinha do Amapá. The adoption of this cultivar by small cassava growers in regions where this crop remains one of the main staples may address the shortage of vitamin A in their diets. Amarelinha do Amapá could also be used for improving carotenoid content in cassava breeding. 


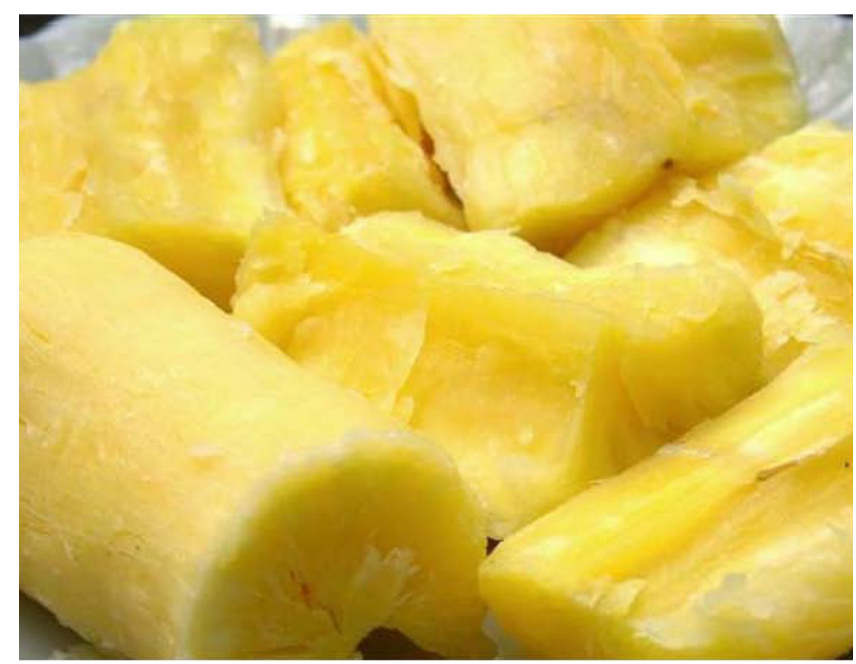

Figure 2. Cooked root of Amarelinha do Amapá.

\section{ACKNOWLEDGMENTS}

Research supported by the Brazilian National Council for Scientific Development, Brasília (CNPq). The above living collection was established at University of Brasília with the help of the Canadian International Development Research Center (IDRC) to whom we are grateful.

\section{REFERENCES}

Britton G (1995). UV/Visible Spectroscopy. In: Carotenoids. Vol. 1b. Spectroscopy (Britton G, Linae-Jensen S and Pfender H, eds.). Birkhäuser, Basel, 13-62.

Davies BH (1976). Carotenoids. In: Chemistry and Biochemistry of Plant Pigments. Vol. 2 (Goodwin TW, ed.). Academic Press, London, 38-155.

FAO (Food and Agriculture Organization) (2006). Production Yearbook. Food and Agriculture Organization of the United Nations, Rome.

Krinsky NI (1994). The biological properties of carotenoids. Pure Appl. Chem. 66: 1003-1010.

Nassar NMA (1978). Conservation of cassava genetic resources: Determination of wild species localities with emphasis on probable origin. Econ. Bot. 32: 311-320.

Nassar NM (2002). Cassava, Manihot esculenta Crantz, genetic resources: origin of the crop, its evolution and relationships with wild relatives. Genet. Mol. Res. 1: 298-305.

Nassar NM (2003). Gene flow between cassava, Manihot esculenta Crantz, and wild relatives. Genet. Mol. Res. 2: 334-347.

Nassar NMA, Vizzoto CS, Silva HL, Schwartz CA, et al. (2005). Potentiality of cassava cultivars as a source of carotenoids. Gene Conserv. 4: 257-283.

Nassar N, Vizzotto CS, Schwartz CA and Pires OR Jr (2007). Cassava diversity in Brazil: the case of carotenoid-rich landraces. Genet. Mol. Res. 6: 116-121.

Taylor KL, Brackenridge AE, Vivier MA and Oberholster A (2006). High-performance liquid chromatography profiling of the major carotenoids in Arabidopsis thaliana leaf tissue. J. Chromatogr. A 1121: 83-91. 